gov/IOTD/view.php?id=84819. Published December 2, 2014. Accessed October 1, 2015.

2. Smith J. Local Cape Verdeans join to support volcano victims. The Boston Globe. https://www.bostonglobe.com/metro/2014/12/07/local-cape-verdeansjoin-support-volcano-victims/8toZME1G4hBEdhYCugcMKO/story.html. Published December 8, 2014. Accessed July 16, 2015.

3. Tobin GA, Whiteford LM. Community resilience and volcano hazard: the eruption of Tungurahua and evacuation of the faldas in Ecuador. Disasters. 2002;26(1):28-48.
4. Savoia E, Lin L. Engaging the diaspora in assessing population needs after the 2014 Cape Verde volcano eruption. Harvard T.H. Chan School of Public Health website. http://www.hsph.harvard.edu/preparedness/ research_evaluation/evaluation/us/international-activities/population-needsafter-the-2014-cape-verde-volcano-eruption/. Accessed December 18, 2015.

5. UN Web TV. The Role of Diaspora During and After Crisis Situations Side Event to the ECOSOC Humanitarian Affairs Segment Organized by the International Organization for Migration (IOM) [video]. http://webtv.un.org/ watch/the-roleof-diaspora-during-and-after-crisis-situations/3642043201001. Published June 25, 2014. Accessed October 1, 2015.

\title{
Voluntary Medical Support Is Key After Nuclear Disasters
}

\author{
Tomohiro Morita, MD; Masaharu Tsubokura, MD; Tsuyoshi Nemoto, MD; \\ Tomoyoshi Oikawa, MD; Yukio Kanazawa, MD
}

$\mathrm{T}$ he contribution of voluntary support by medical staff is increasingly important during nuclear, biological, and chemical (NBC) disasters. A report highlighted the important role of Médecins Sans Frontières (MSF) during the Ebola outbreak. ${ }^{1}$ We acknowledge the important contributions from voluntary medical providers, which we experienced after the Fukushima Daiichi Nuclear Power Plant accident on March 12, 2011.

Here, we would like to share our experience. The Japanese government established a mandatory evacuation zone for a $20-\mathrm{km}$ radius around the plant. This made our hospital, located $23 \mathrm{~km}$ from the plant, the closest hospital to the plant to continue operating. However, 6 of 13 doctors and 80 of 164 nurses in our hospital had evacuated after the nuclear accident on March 12, 2011. As a result of the decreased staffing, we were not in a position to provide adequate care to hospitalized patients. ${ }^{2}$

Moreover, support from the government was withdrawn as the nuclear situation worsened. Although the government sent 178 medical workers on March 12, the entire team evacuated in 3 days. Similarly, on March 15 the Japan Red Cross Society made the decision not to send any relief teams to a $30-\mathrm{km}$ radius around the nuclear plant.

In contrast to this lack of official support, we received voluntary support. From March 20, 2011, to November 30, 2012, a total of 275 medical staff came on their own volition to provide clinical support to our hospital (Figure 1). They also contributed to post-disaster research by increasing the number of patients participating. Consequently, we were able to investigate the internal radiation dose of $98 \%$ of elementary and junior high school students. ${ }^{3}$ In the end, the voluntary assistance of medical professionals was more influential than support from governmental or nongovernmental institutions, from both clinical and research perspectives.
NBC disasters, natural or manmade, can happen anywhere in the world. We should be aware of the limitations to governmental support. Voluntary support may have the biggest impact on recovery and post-disaster research, as seen in the Fukushima disaster and the Ebola outbreak.

\section{About the Authors}

Soma Central Hospital, Soma City, Fukushima, Japan, (Dr Morita); Division of Social Communication System for Advanced Clinical Research, Institute of Medical Science, The University of Tokyo, Minato-ku, Tokyo, Japan (Drs Morita and Tsubokura); and Minamisoma Municipal General Hospital, Minamisoma City, Fukushima, Japan (Drs Nemoto, Oikawa, and Kanazawa).

Correspondence and reprint requests to Tomohiro Morita, Internal Medicine, Soma Central Hospital, 3-5-18, Okinouchi, Soma City, Fukushima, Japan (e-mail: t.morita526@gmail.com).

Published online: February 1, 2016.

\section{FIGURE 1}

\section{A Picture of Voluntary Medical Staff on March $21,2011$.}

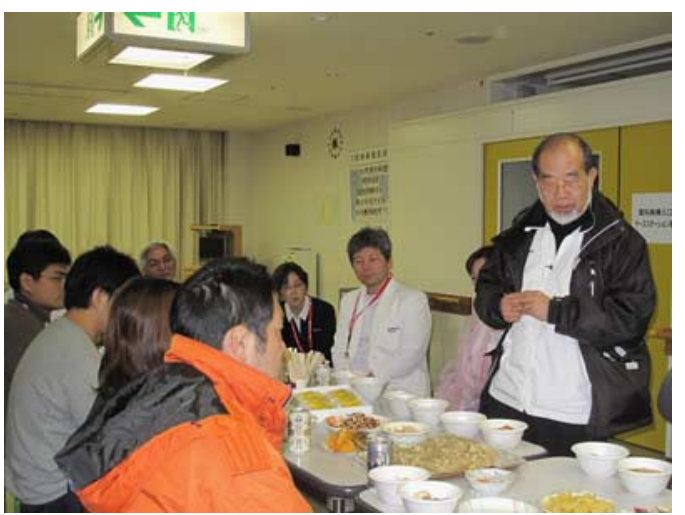




\section{REFERENCES}

1. Check Hayden E. Ebola outbreak thrusts MSF into new roles. Nature. 2015;522(7554):18-19. http://dx.doi.org/10.1038/522018a.

2. Kodama Y, Oikawa T, Hayashi K, et al. Impact of natural disaster combined with nuclear power plant accidents on local medical services: a case study of Minamisoma Municipal General Hospital after the Great
East Japan Earthquake. Disaster Med Public Health Prep. 2014;8:471-476. http://dx.doi.org/10.1017/dmp.2014.112.

3. Tsubokura M, Kato S, Morita T, et al. Assessment of the annual additional effective doses amongst Minamisoma children during the second year after the Fukushima Daiichi nuclear power plant disaster. PLoS One. 2015;10(6):e0129114. http://dx.doi.org/10.1371/journal. pone.0129114.

doi:10.1017/dmp.2015.180

\title{
Critical Guidelines for Health Care Workers Who Deploy to West Africa for the Ebola Response
}

\author{
Viroj Wiwanitkit, MD, FRFM
}

$\mathrm{T}$

The recent report "Academic Institutions' Critical Guidelines for Health Care Workers Who Deploy to West Africa for the Ebola Response and Future Crises" was very interesting. ${ }^{1}$ Cranmer et al mentioned a "lack of sufficient and qualified [health care workers]." In fact, a team of volunteers to work in West Africa assisting those affected by the outbreak is a good thing. However, good preparation for a team of volunteers before an actual mission is necessary. At least, there should be a short training course on the new disease before health care workers are allowed to enter the outbreak area. ${ }^{2}$ Patel et al noted that "existing community health programs can be used as a platform to train volunteer health advisors in times of epidemics for quick dissemination of vital health information in areas lacking adequate health infrastructure and personnel." ${ }^{\text {3 }}$ Finally, preparation for management of possible infected volunteer health care workers is required. There must be a good primary management and a referring back system.

\section{About the Authors}

Hainan Medical University, China (visiting); Faculty of Medicine, University of Nis, Serbia (visiting); Joseph Ayobabalola University, Nigeria (adjunct); and Dr DY Patil Medical University, India (honorary).
Correspondence and reprint requests to Prof Viroj Wiwanitkit, Wiwanitkit House, Bangkhae, Bangkok, Thailand 10160 (e-mail: wviroj@yahoo.com).

Published online: January 29, 2016.

\section{REFERENCES}

1. Cranmer H, Aschkenasy M, Wildes R, et al. Academic institutions' critical guidelines for health care workers who deploy to West Africa for the Ebola response and future crises. Disaster Med Public Health Prep. 2015;9(5):586-590.

2. Lupton K. Preparing nurses to work in Ebola treatment centres in Sierra Leone. Br J Nurs. 2015;24(3):168-172. http://dx.doi.org/10.12968/ bjon.2015.24.3.168.

3. Patel U, Pharr JR, Ihesiaba C, et al. Ebola outbreak in Nigeria: increasing Ebola knowledge of volunteer health advisors. Glob J Health Sci. 2015; 8(1):72-78. http://dx.doi.org/10.5539/gjhs.v8n1p72. 